\title{
Building divergent body plans with similar genetic pathways
}

\author{
BJ Swalla ${ }^{1,2,3}$ \\ ${ }^{1}$ Center for Developmental Biology, Department of Biology, University of Washington, Seattle, WA 98195-1800, USA; ${ }^{2}$ Friday Harbor \\ Laboratories, University of Washington, Friday Harbor, WA 98250-9299, USA; ${ }^{3}$ Smithsonian Marine Station, 701 Seaway Drive, Fort \\ Pierce, FL 34949-3140, USA
}

\begin{abstract}
Deuterostome animals exhibit widely divergent body plans. Echinoderms have either radial or bilateral symmetry, hemichordates include bilateral enteropneust worms and colonial pterobranchs, and chordates possess a defined dorsal-ventral axis imposed on their anterior-posterior axis. Tunicates are chordates only as larvae, following metamorphosis the adults acquire a body plan unique for the deuterostomes. This paper examines larval and adult body plans in the deuterostomes and discusses two distinct ways of evolving divergent body plans. First, echinoderms and hemichordates have similar feeding larvae, but build a new adult body within or around their larvae. In hemichordates and many direct-developing echinoderms, the adult is built onto the larva, with the larval axes becoming the adult axes and the larval mouth becoming the adult mouth. In contrast, indirect-developing echinoderms undergo radical metamorphosis where adult axes are not the same as larval axes. A
\end{abstract}

second way of evolving a divergent body plan is to become colonial, as seen in hemichordates and tunicates. Early embryonic development and gastrulation are similar in all deuterostomes, but, in chordates, the anterior-posterior axis is established at right angles to the animal-vegetal axis, in contrast to hemichordates and indirect-developing echinoderms. Hox gene sequences and anterior-posterior expression patterns illuminate deuterostome phylogenetic relationships and the evolution of unique adult body plans within monophyletic groups. Many genes that are considered vertebrate 'mesodermal' genes, such as nodal and brachyury $T$, are likely to ancestrally have been involved in the formation of the mouth and anus, and later were evolutionarily co-opted into mesoderm during vertebrate development. Heredity (2006) 97, 235-243. doi:10.1038/sj.hdy.6800872; published online 26 July 2006

Keywords: chordate evolution; body plans; coloniality; tunicates; hemichordates; evolution and development

\section{Deuterostome phylogenetic relationships}

Deuterostome phylogenetic relationships have been reviewed extensively elsewhere (Schaeffer, 1987; Cameron et al, 2000; Bourlat et al, 2003; Smith et al, 2004; Blair and Hedges, 2005; Zeng and Swalla, 2005; Delsuc et al, 2006) so will be briefly discussed here. Deuterostomes are monophyletic, and include two great clades: Ambulacraria, which consists of Echinodermata and Hemichordata (Figure 1I; Cameron et al, 2000; Peterson, 2004; Smith et al, 2004), and Chordata, which consists of Tunicata, Cephalochordata (lancelets), and Vertebrata (Figure 1II; Cameron et al, 2000; Zeng and Swalla, 2005). Xenoturbellida, a potentially new phylum of the Deuterostomia that has been described, is thought to be related to the Ambulacraria, but the exact placement within the deuterostomes is not yet clear (Bourlat et al, 2003).

There is a plethora of evidence for echinoderms and hemichordates as sister groups (Peterson, 2004; Smith et al, 2004; Zeng and Swalla, 2005), so features that hemichordates share with chordates were likely to have been present in the deuterostome ancestor (Gerhart et al,

Correspondence: BJ Swalla, Department of Biology, University of Washington, Box 351800, 24 Kincaid Hall, Seattle, WA 98195, USA

E-mail: bjswalla@u.washington.edu

Received 1 January 2006; accepted 2 June 2006; published online 26 July 2006
2005; Rychel et al, 2006). There is both molecular and morphological evidence that the Ambulacraria are monophyletic (Cameron et al, 2000; Peterson, 2004; Smith et al, 2004). Similarities in the larvae of echinoderms and hemichordates have been noted for years (Figure 2; Morgan, 1891; Dautov and Nezlin, 1992; Strathmann and Eernisse, 1994; Nielsen, 1997) and echinoderms and hemichordates have recently been shown to share motifs in three posterior Hox genes, Hox 11/13a, 11/13b and 11/ $13 c$, as discussed later (Peterson, 2004). This raises the interesting question of how the two phyla have such different adult body plans, when they have such similar larvae.

Conversely, within chordates, Tunicata is the only subphylum that is classified by larval, rather than adult characteristics (Zeng and Swalla, 2005). Tunicates are monophyletic (Swalla et al, 2000) and have a unique adult body plan, including the cellulose tunic, as discussed in Zeng and Swalla (2005). It is difficult to place tunicates reliably within the deuterostomes, due to the long branches found for most of their genes (Winchell et al, 2002; Blair and Hedges, 2005; Zeng and Swalla, 2005). Interestingly, new genome analyses suggest that tunicates are more related to vertebrates than cephalochordates, but these results could be an artifact of incomplete data from cephalochordates and hemichordates (Blair and Hedges, 2005; Philippe et al, 2005; Delsuc et al, 2006). Understanding the position of the tunicates 


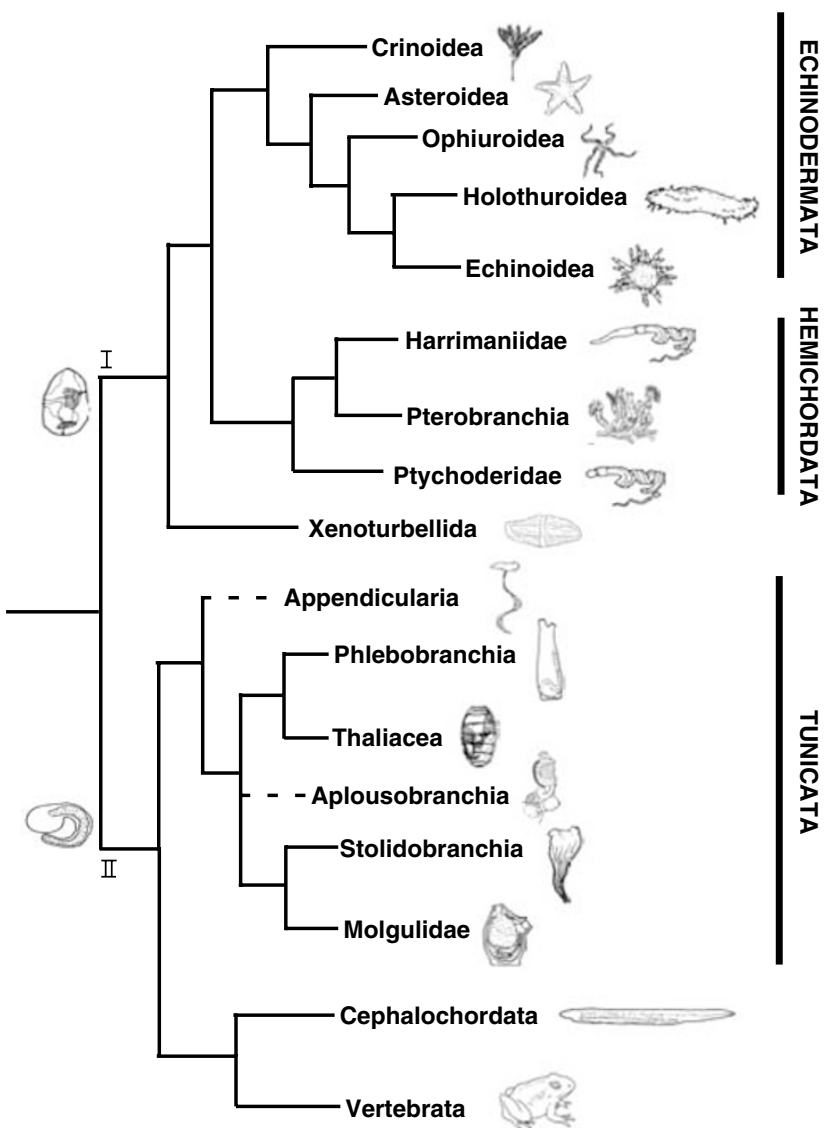

Figure 1 Current deuterostome phylogeny, with the three major invertebrate clades marked on the right: Echinodermata, Hemichordata and Tunicata. Vertebrates and Cephalochordata (lancelets) form a fourth clade, Chordata. Ciliated Ambulacraria larvae (I) and Tunicata tadpole larvae (II) are likely to have separate origins. Uncertainties in the Tunicata phylogeny are marked by dotted lines. Modified from Zeng and Swalla (2005).

within the deuterostomes will require continued phylogenetic and genomic analyses, coupled with careful studies of evolutionary and developmental processes, including analyses of gene networks (Davidson and Erwin, 2006).

\section{Early development in the deuterostomia}

All deuterostomes gastrulate at the vegetal pole, thus the blastopore is formed at or near the vegetal pole, later becoming the anus (Chea et al, 2005). However, the chordate larvae of ascidians have completely different structures and functions than the larvae of echinoderms and hemichordates (Figure 2; Ettensohn et al, 2004). Many echinoderm and hemichordate species have feeding larvae that capture food by ciliary motion and can spend months feeding in the plankton (Figure 2; Dautov and Nezlin, 1992; Strathmann and Eernisse, 1994; Nielsen, 1997). On the other hand, chordate ascidian larvae are nonfeeding, and must metamorphose in order to be able to feed (Figure 2; Davidson et al, 2004). We believe that these larvae have independent evolutionary origins (Zeng and Swalla, 2005). Ascidian embryos and larvae share many genetic pathways with chordate embryos (Passamaneck and Di Gregario, 2005), while
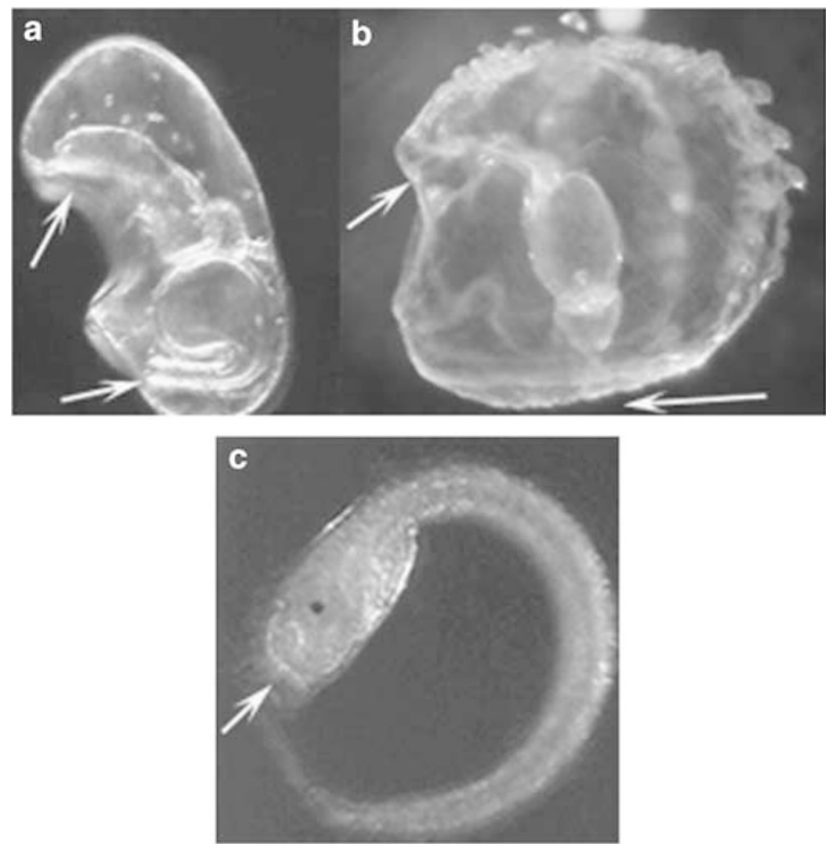

Figure 2 Deuterostome larvae, showing (a) a sea star echinoderm larvae, (b) a hemichordate tornaria larva and (c) a tunicate larva, all oriented with the mouth to the left and anus to the bottom. (a) Sea star larvae have an anterior (top left), which was the original animal pole of the egg. (b) Anterior in the hemichordate tornaria larva is the apical tuft (top of photo). (a, b) Both of these larvae feed with ciliary beating and have well-developed guts and coeloms. The mouth of the sea star and hemichordate larvae are seen to the left (arrow). The posterior anus forms at the former vegetal pole (arrows at bottom). In hemichordates, the larval mouth becomes the adult mouth and the proboscis develops anterior to the mouth. The gill slits and abdomen of the worm will develop posteriorly. (c) The tunicate larva is nonfeeding and lacks a heart, blood and gut, which will develop after metamorphosis. An arrow marks the anterior, where the mouth will form after metamorphosis, but is not yet open. There is no anus at this stage.

echinoderms and hemichordates share similar genetic pathways during the embryonic and larval stages (Shoguchi et al, 1999). In hemichordates and indirectdeveloping echinoderms, the animal-vegetal axis of the egg becomes the anterior-posterior axis of the larva, so a mouth is formed secondarily at the location where the archenteron contacts the ectoderm (Figures 2-4; Chea et al, 2005). In contrast, in chordates, gastrulation results in the movement of large amounts of mesoderm into the archenteron, in order to form the notochord and the surrounding muscular somites, so the anterior-posterior axis lies at a right angle to the animal-vegetal axis (Chea et al, 2005).

\section{Different adult body plans built from similar larvae}

Hemichordate tornaria larvae are similar morphologically to the bipinnaria larvae of sea stars and the auricularia larvae of sea cucumbers (Figures 2-4; Dautov and Nezlin, 1992; Strathmann and Eernisse, 1994; Urata and Yamaguchi, 2004). This type of larva, with a distinct gut and three coeloms has been called collectively a dipleurulid larva (Nielsen, 1997). Development of a 


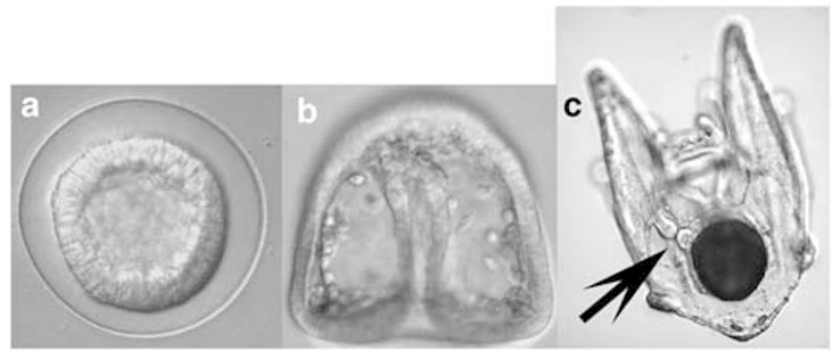

Figure 3 Echinoid development (a). Early blastula shows a thickening at the vegetal pole (bottom of the photo), where gastrulation will begin. (b) The archenteron invaginates at the vegetal pole (bottom of the photo), which will become the anus, and the mouth is formed to the left side in this photo, where the archenteron touches the ectoderm. This is also the site of nodal and brachyury expression in sea urchins (Duboc et al, 2004; Peterson et al, $1999 \mathrm{~b}$ ). (c) Later, the adult rudiment is formed where the ectoderm touches the larval coelom on the left side of the larva (arrow). This is opposite the second site of nodal expression in sea urchin larvae (Duboc et al, 2005)
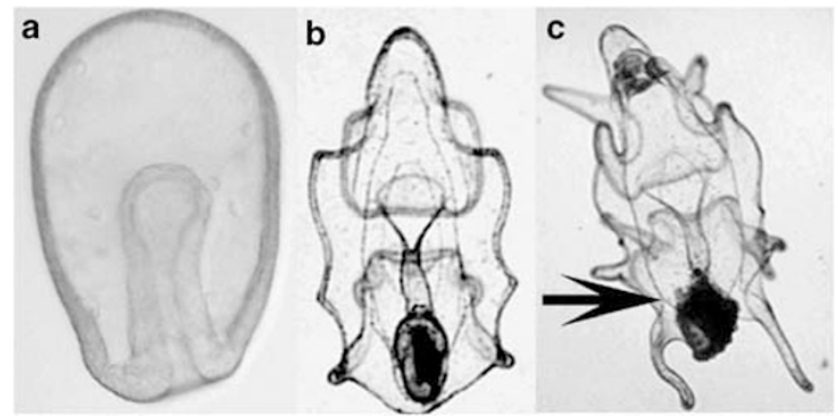

Figure 4 Sea star development (a). Sea stars gastrulate similarly to sand dollars, with the vegetal pole the site of archenteron formation (bottom of the photo), although the mouth is formed more at the midpoint of the larva. (b) Later, in the bipinnaria larva, the adult rudiment is seen as new pigmentation, forming in the posterior of the larva. (c) The advanced brachiolaria larva shows the anteriorposterior larval organization, while the radial adult is formed at the posterior of the animal (arrow). After metamorphosis, the tiny new radial sea star will engulf the rest of the bilateral larva.

hemichordate planktonic larvae and its complete metamorphosis into an enteropneust worm, Balanoglossus misakiensis, has recently been published (Urata and Yamaguchi, 2004). This study documents larval and adult structures throughout early development and metamorphosis in an enteropneust worm with tornaria larvae (Urata and Yamaguchi, 2004). The authors show that the hemichordate adult body plan is elaborated onto the larval body plan (Urata and Yamaguchi, 2004), as suggested by earlier studies (Morgan, 1891; Hadfield, 1975). Balanoglossus misakiensis embryos gastrulates at the vegetal pole and the blastopore at the vegetal pole becomes the anus (Urata and Yamaguchi, 2004; Chea et al, 2005). The mouth is formed secondarily to the side when the archenteron touches the ectoderm, similarly to echinoderm embryos (Figures 3 and 4). An apical tuft is formed at the anterior, where the animal pole was located in the fertilized egg (Figure 2; Hadfield, 1975). After metamorphosis, the nerves of the apical tuft degenerate and the proboscis coelom is formed, developing a proboscis at the very anterior of the animal (Figure 2; Urata and Yamaguchi, 2004). The larval mouth becomes the adult mouth of the worm, located in the collar region, while the posterior of the enteropneust worm is elaborated by growth posterior to the neck region (Urata and Yamaguchi, 2004). In summary, in enteropneust hemichordates, the adult body plan is dramatically different inmorphology from the larval body plan, but the adult retains the same anteriorposterior and oral-aboral axes.

In contrast, indirect-developing echinoderms exhibit a radical metamorphosis, where the axes of the adult body plan do not necessarily correspond to the larval body axes (Figures 3 and 4). For example, in echinoids, the touching of invaginating ectoderm and coelom will mark where the adult rudiment forms inside of the pluteus larva (Figure 3). The same pattern is seen in sea stars as shown in Figure 4. The adult sea star, with fivefold symmetry, emerges from a bilateral larva. The larval anterior was the original animal pole of the fertilized egg, and the posterior is the anus, where the blastopore was formed (Figure 4). Smith et al (2004) discuss how it is likely that the echinoderm ancestor was a bilateral adult and that the prevalence of pentaradial symmetry in extant forms involved a mass extinction of many clades of echinoderms.

In summary, if the Ambulacraria were classified on larval morphology, they would be considered one phylum. Instead, they are divided into separate phyla, echinoderms and hemichordates, based on adult morphology. The echinoderms have a derived body plan, many groups show pentaradial adult symmetry, and all extant echinoderms lack gill slits (Smith et al, 2004). It has been noted that hemichordates share gill slits with the chordates, so the deuterostome ancestor was likely a benthic worm-like creature with gill slits (Cameron et al, 2000; Bourlat et al, 2003; Peterson, 2004; Gerhart et al, 2005; Zeng and Swalla, 2005; Rychel et al, 2006). When one examines chordate features, hemichordates share at least three of these morphological characters: the gill slits, an endostyle and a postanal tail (Gerhart et al, 2005; Rychel et al, 2006). The simplest interpretation of these results is the chordate ancestor was worm-like, with an endostyle, a postanal tail and gill slits. The key chordate innovation, then, was the evolution of a notochord and a dorsal neural ectoderm with the resulting loss of an ectodermal nerve net in the adult (Swalla, 2006).

\section{Coloniality is a fast track to new body plans}

In both hemichordates and tunicates, very different body plans evolved by switching from a solitary to a colonial life history and perhaps even vice versa, from colonial to a solitary mode (Cameron et al, 2000; Zeng and Swalla, 2005; Zeng et al, 2006). Hemichordate phylogenies have shown that the colonial pterobranchs may be more closely related to the Harrimaniids, which have direct developing larvae, than to the Ptychoderids (Figure 1; Halanych, 1995; Cameron et al, 2000). Tunicate phylogenies show that the evolution of coloniality has occurred several times independently in tunicates (Swalla et al, 2000) and within ascidians (Wada et al, 1992; Zeng et al, 2006; Yokobori et al, 2006).

There are several consequences of evolving a colonial lifestyle from a solitary one, which affect adult axes and mode of reproduction (Figure 5; Davidson et al, 2004). 


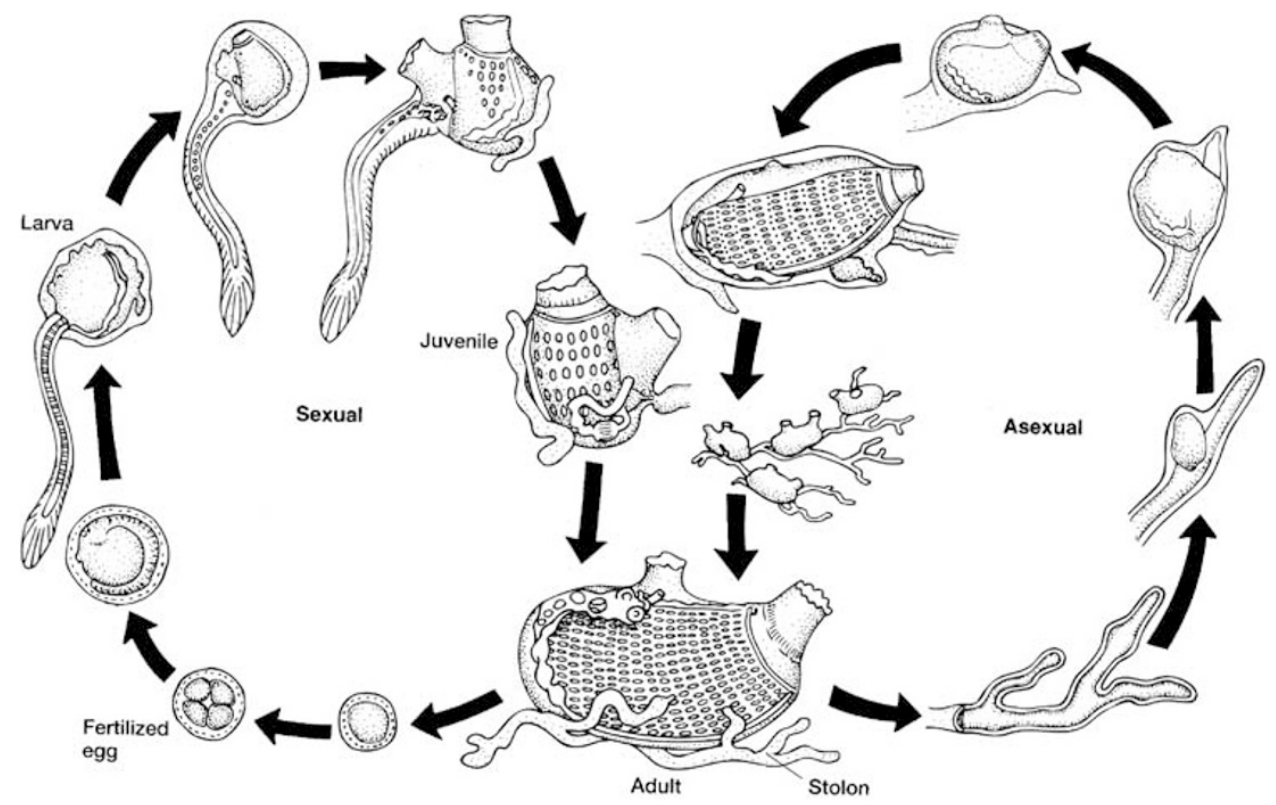

Figure 5 Coloniality in tunicates - a schematic diagram of the development of colonial ascidians. On the left is shown embryonic development into a tadpole larva, going through metamorphosis. On the right is a colonial ascidian in the process of budding. An exact replica of the adult can be formed either by a tadpole or by budding in colonial species. Used with permission from Kardong (2006).

First, there is usually a miniaturization of the adult when comparing closely related solitary and colonial species (Kardong, 2006; Zeng et al, 2006). This is also normally accompanied by changes in polarity, as colonial species form a superstructure of individuals (Zeng et al, 2006). Finally, in colonial species, asexual reproduction goes on continuously by budding to form new individuals (Figure 5; Kardong, 2006). In contrast, solitary species reproduce solely by sexual reproduction (Figure 5; Davidson et al, 2004). Colonial species also brood their larvae, and spawn competent larvae that are ready to settle (Davidson et al, 2004; Zeng et al, 2006). These life history and body plan changes, miniaturization, budding, and brooding, are seen in the evolution of coloniality in both hemichordates (Cameron et al, 2000) and tunicates (Davidson et al, 2004).

There are no known extant deuterostome species that can switch from a solitary to colonial lifestyle. In extant deuterostomes, one sees closely related species that are colonial or solitary, and an intermediate social phenotype that may be an evolutionary step in becoming colonial (Zeng et al, 2006). However, in some aplousobranch colonial ascidians, reproduction continues asexually unless the possibility of outcrossing is detected through nonself sperm in the water (Bishop et al, 2000). As basal metazoans (cnidarians) have some solitary species, some colonial species and some species that are capable of switching life histories, it is possible that the deuterostome ancestor was capable of either a colonial lifestyle with asexual reproduction or a solitary lifestyle with sexual reproduction or a combination of both life histories (Davidson et al, 2004). In the evolution of echinoderms and chordates, especially in the cephalochordate/vertebrate lineage, the colonial lifestyle and asexual reproduction capacities were lost, after which all species became solitary and exclusively sexual.

In addition, it appears that echinoderm larvae have the ability to clone themselves when they are in the plankton for long periods of time (Eaves and Palmer, 2003; Knott et al, 2003). Under controlled laboratory conditions, the clones have been shown to be able to metamorphose and form normal juveniles (Eaves and Palmer, 2003; Knott et al, 2003). It is not yet known whether hemichordate tornaria larvae also have the ability to clone, but it would be an interesting finding. Solitary tunicate larvae and adults have not been reported to be able to clone, but colonial tunicates can form a new individual from single epidermal ampullae (Rabinowitz and Rinkevich, 2003). This capacity for cloning and regeneration in nonvertebrate deuterostomes has not received the attention and interest that it deserves. It is likely that the genetic programs involved in larval cloning and colonial budding will be similar to the programs necessary for regeneration and stem cell renewal (Laird et al, 2005). These processes will likely share genetic pathways across the deuterostomes, including vertebrates and humans.

\section{Hox developmental gene expression in deuterostomes}

One of the key innovations during the evolution of vertebrates was the duplication of developmental genes, including the clusters of homeobox gene transcription factors that are involved in anterior-posterior patterning in both protostomes and deuterostomes (Figure 6; Carroll, 1995). While ascidians (Di Gregorio et al, 1995; Spagnuolo et al, 2003) and lancelets (amphioxus) (Holland et al, 1994; Wada et al, 1999) have only a single Hox cluster, tetrapods have four clusters (Wada et al, 1999) and teleost fish have eight clusters (Figure 6; Amores et al, 1998; Meyer and Malaga-Trillo, 1999). In vertebrate embryos (Holland et al, 1994; Carroll, 1995), lancelet (Holland et al, 1994; Wada et al, 1999) and ascidian larvae (Di Gregorio et al, 1995; Spagnuolo et al, 2003) expression of the Hox genes proceeds in a collinear temporally and 


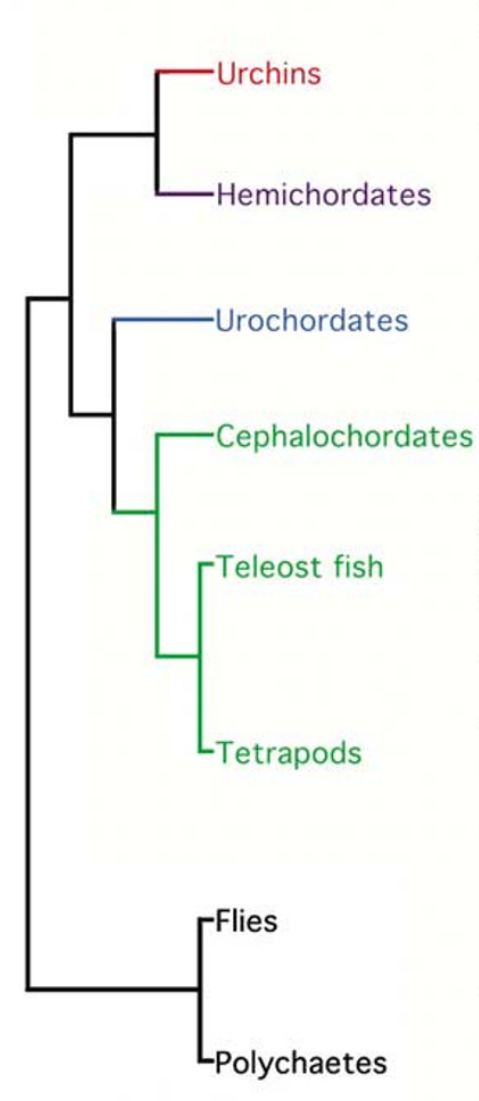

PHYLOGENY
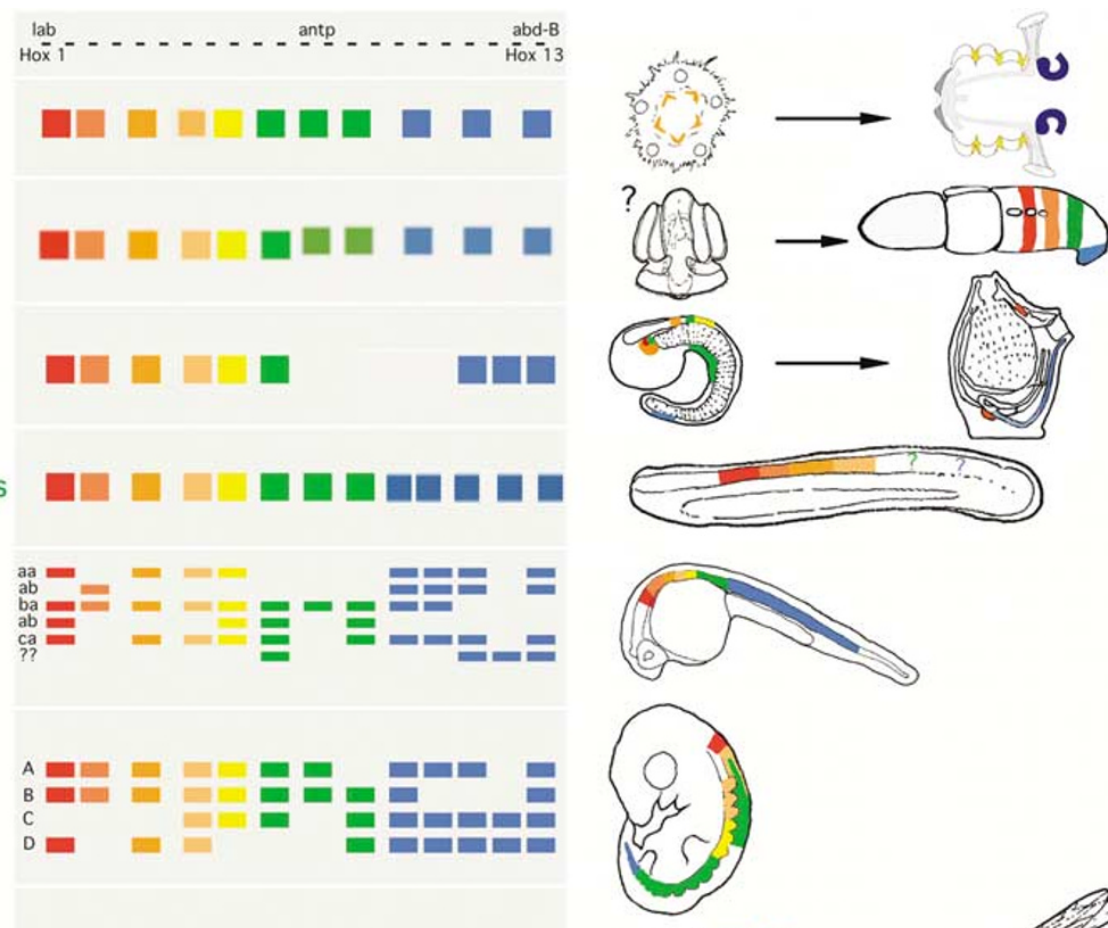

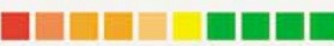

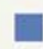

口丩 $\square \square \square \square \square$

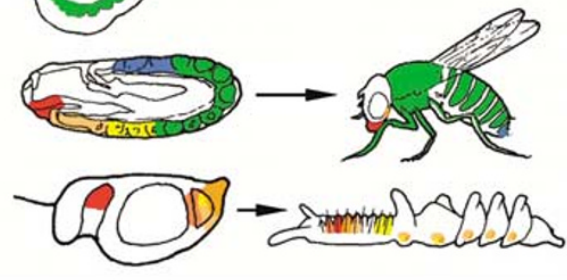

KNOWN EXPRESSION

Figure 6 Expression of Hox genes in deuterostomes - the Hox gene cluster is duplicated in vertebrates. There are eight Hox gene clusters in teleost fishes, showing an additional duplication from the four Hox gene clusters found in the tetrapod vertebrates. In contrast, the invertebrate deuterostomes each have a single cluster. Ascidians lack some of the middle Hox genes, and the cluster is broken up onto two chromosomes. Echinoderms and hemichordates share an independent duplication of the posterior genes, called Hox 11/13a, Hox 11/13b and Hox 11/13c. Hemichordates show anterior to posterior expression in the ectoderm, which will produce a nerve net later in development. Echinoderms show adult expression in the nerve ring with the oral side corresponding to anterior in chordates and hemichordates.

spatially defined pattern from anterior to posterior (Figure 6). In all of the invertebrate deuterostomes there is a single Hox cluster. In echinoderm and hemichordate Hox clusters (Martinez et al, 1999; Long et al, 2003), the posterior Hox genes share motifs, suggesting that they diverged independently from the posterior Hox genes in the chordates (Peterson, 2004; Figure 6). In hemichordates, the expression of the Hox genes is in an anterior to posterior manner, with the anterior genes being expressed in the proboscis, and the posterior genes expressed in the postanal tail (Lowe et al, 2003; Figure 6). The expression of Hox genes in sea urchins initially did not appear to proceed in a colinear manner during embryonic development (Popodi et al, 1996; ArenasMena et al, 1998; Martinez et al, 1999). However, recent studies in a direct developing sea urchin suggest that the oral-aboral axis of echinoid echinoderms is similar to the anterior-posterior axis of hemichordates and chordates (Morris and Byrne, 2005). Furthermore, most of the Hox genes in the cluster are expressed only during the development of the adult, and so far only two show any early larval expression (Arenas-Mena et al, 1998; Martinez et al, 1999; Morris and Byrne, 2005). For Hox cluster members 6-11/13, expression is detected during late larval development in nested domains of the posterior coeloms; cluster member six is expressed in the anterior part and 11/13 in the posterior part with the intervening genes exhibiting overlapping domains (Martinez et al, 1999). These results suggest that the larvae of echinoderms and hemichordates may have evolved secondarily in the Ambulacraria clade of the deutero stomes. It is interesting that Hox 1, the most anterior Hox gene, is expressed just after the first gill slit forms in hemichordates and in vertebrates, suggesting that the positioning of the gill slits along the anterior-posterior axis is homologous (Lowe et al, 2003; Gerhart et al, 2005; Rychel et al, 2006; Figure 6).

\section{Nodal gene expression and left-right asymmetry}

Nodal is a member of the TGF $\beta$ superfamily of signaling molecules found in all phyla of deuterostomes, but nodal has not yet been reported in the Ecdysozoa or Lophotrochozoa (Chea et al, 2005). Nodal and the entire nodal signaling cascade of genes is expressed early during gastrulation during the formation of mesoderm in 
vertebrates and lancelets as reviewed in Chea et al (2005). Later, nodal is expressed on the left side of chordate embryos and is necessary for left-right asymmetry (Chea et al, 2005). In light of these results, the expression and function of nodal in echinoderms and hemichordates is very interesting.

Nodal expression has been reported in sea urchins at the site where the mouth forms during gastrulation, and has been shown to pattern the oral-aboral axes in the developing embryo and pluteus larvae (Duboc et al, 2004; Flowers et al, 2004; Figures 2-4). Later, nodal is also expressed opposite the site of the adult rudiment formation in larval urchins, which normally forms on the left side of the larvae (Duboc et al, 2005; Figures 2-4). It is intriguing that nodal serves multiple functions during deuterostome development, a theme that is fundamental to the evolution of developmental processes (Davidson and Erwin, 2006). Nodal expression is found in the developing mouth in the direct-developing hemichordate, Saccoglossus kowalevskii, similar to the early echinoderm expression (Christopher J. Lowe, personal communication). Later expression of nodal in hemichordates might be interesting and informative as to how the hemichordate left-right axes correspond to chordate axes (Chea et al, 2005; Gerhart et al, 2005).

\section{Brachyury gene expression}

A novel tissue, the notochord, unites the chordates as a monophyletic group (Figures 1 and 7). Notochord is necessary as a developmental signaling tissue during neural tube formation and also remains as a structural tail tissue in ascidian larvae and cephalochordates (Smith and Schoenwolf, 1989). One transcription factor known to be necessary for notochord development in chordate embryos is the T-box transcription factor brachyury $T$ (Holland et al, 1995). Brachyury $T$ is expressed in developing notochord cells in vertebrates (Wilkinson et al, 1990), lancelets (Holland et al, 1995), ascidians (Yasuo and Satoh, 1993, 1994) and larvaceans (Bassham and Postlethwait, 2000) (Figure 7). In lancelet and vertebrate embryos, brachyury $T$ is expressed early in presumptive mesoderm, and later in the notochord and posterior mesoderm (Holland et al, 1995; Figure 7). However, in ascidians, brachyury $T$ expression was seen only in the notochord, at the time of cell fate restriction (Yasuo and Satoh, 1993, 1994). As brachyury $T$ is expressed exclusively in the ascidian notochord (Yasuo and Satoh, 1993, 1994), it was believed that the expression of brachyury $T$ in echinoderms (Shoguchi et al, 1999; Peterson et al, 1999b) and hemichordates (Tagawa et al, 1998; Peterson et al, 1999a) might allow clues from which tissues the notochord evolved (Figure 7). However, the results of brachyury $T$ gene expression underscore the differences in morphology between nonfeeding ascidian tadpole larvae and feeding larvae of indirect-developing hemichordates and echinoderms (Figure 2).

Brachyury T expression in sea urchins was found early in the vegetal plate at the mesenchyme blastula stage, later in secondary mesenchyme after gastrulation and was absent in sea urchin larvae (Peterson et al, 1999b). As metamorphosis began, expression was seen in the mesoderm of the left and right hydrocoels in the developing adult urchin (Figure 7; Peterson et al, 1999b). In contrast, the pattern of Brachyury T expression

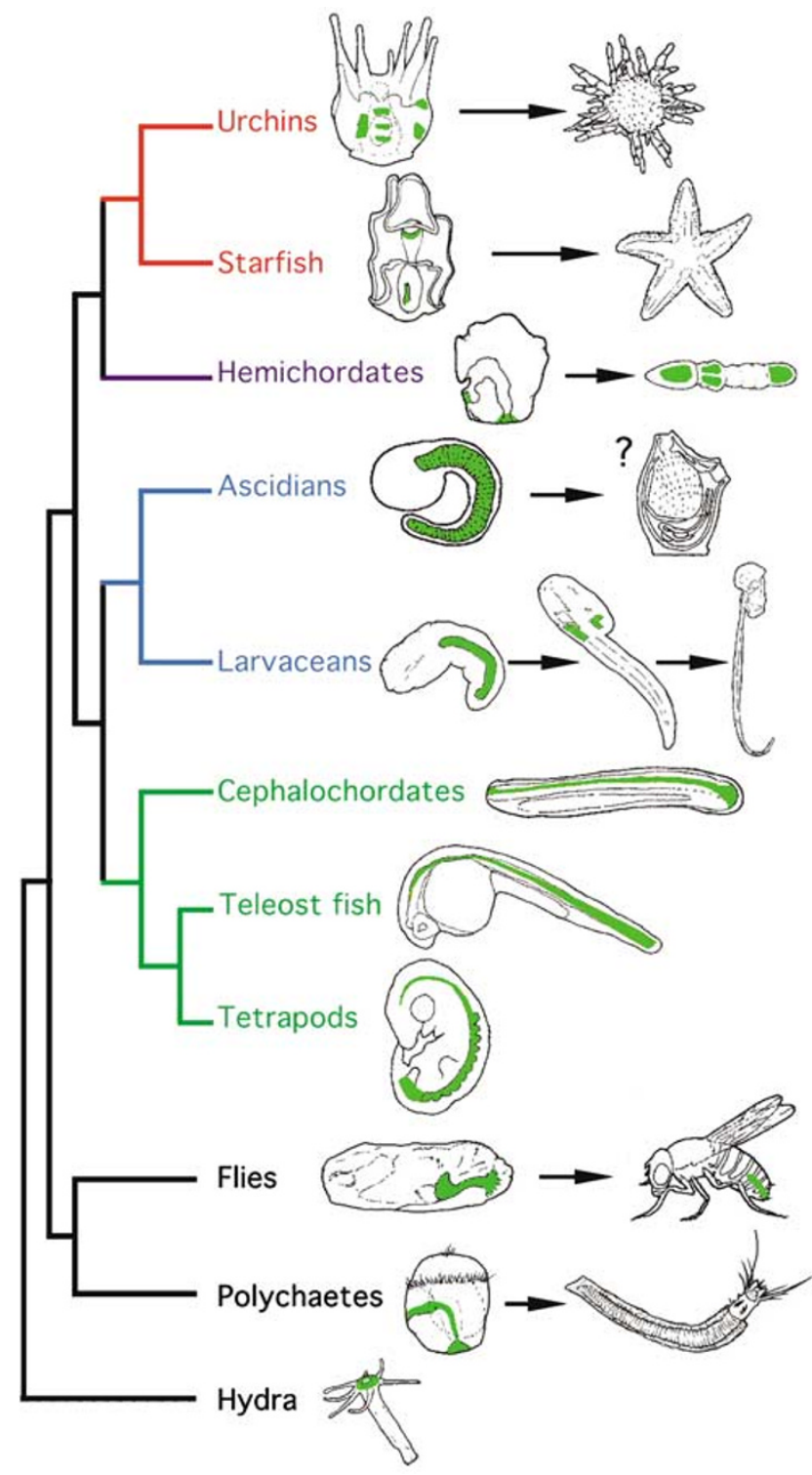

Figure 7 Expression of Brachyury (T) in animals. Brachyury is expressed in the hindgut in flies and in the gut during larval development in polychaete worms. In echinoderms and hemichordates, brachyury is expressed in the anus during gastrulation, then later where the mouth is formed. Brachyury was co-opted into the notochord in chordates, but in larvaceans, it is expressed in notochord and later in the mouth and anus after metamorphosis.

in sea star larvae (Shoguchi et al, 1999) was similar to expression in hemichordate larvae (Tagawa et al, 1998; Peterson et al, 1999a; Figure 7). In hemichordate embryos, expression of brachyury $T$ was first seen in the vegetal plate early in gastrulation (Tagawa et al, 1998). High expression continues at the vegetal plate and finally is still expressed during development of the larval anus (Figure 7; Tagawa et al, 1998; Peterson et al, 1999a). Expression is also seen in the larval mouth from the time of induction by the archenteron (Peterson et al, 1999a). Later, after metamorphosis, expression is high in the adult proboscis, collar, and the posterior region of the trunk and gut (Figure 8; Peterson et al, 1999a). Therefore, the expression of brachyury $T$ in posterior gut is seen in all 
deuterostomes: chordates, echinoderms and hemichordates (Figure 7). In contrast, notochord expression is restricted entirely to the chordates (Figure 7). This separation of expression patterns in tunicates is documented nicely in expression results of brachyury $T$ in larvaceans (Bassham and Postlethwait, 2000). In larvaceans, a pelagic tunicate, expression is first seen only in the larval notochord (Figure 7; Bassham and Postlethwait, 2000). However, after metamorphosis and the development of the gut in the adult, expression is seen in the oral and anal mesoderm (Bassham and Postlethwait, 2000; Figure 7). These results suggest that if brachyury $T$ expression were examined in ascidians after metamorphosis, then there would be expression in the posterior gut. In summary, brachyury T expression patterns suggest that deuterostomes may share a common mesodermal transcription factor for development of the mouth and anus, but no light is shed on the evolutionary origin of the notochord. A screen for genes that are downstream of brachyury $T$ in ascidians has yielded a number of candidates that will be interesting to clone and characterize in hemichordate and echinoderm embryos (Hotta et al, 2000). Brachyury $T$ is also expressed in the hindgut of flies (Lengyel and Iwaki, 2002) and in the mouth and anus of polychaete larvae (Arendt et al, 2001). One idea is that brachyury $T$ is a general transcription factor for a suite of genes that can be activated to allow cell movement, or convergence and extension (Lengyel and Iwaki, 2002). The other possibility is that brachyury $T$ was originally important for ectodermal-endodermal interactions during the formation of the gut and anus (Technau and Scholz, 2003). Later, in chordates, the continued expression of brachyury $T$ on one side of the blastopore may have induced many more cells to ingress opposite of the endoderm, allowing the evolution of the notochord and somites (Chea et al, 2005). An experiment to test this hypothesis would be to over-express brachyury $T$ in hemichordate larvae on one side of the blastopore and determine whether the body axes of the worm are altered as a result of induced expression.

\section{Summary}

Deuterostomes show widely divergent adult body plans in extant taxa. The evolution of these divergent body plans has occurred through different developmental scenarios. Echinoderms and hemichordates share similar larvae, but in hemichordates the adult body plan is built onto the larval body plan, whereas in echinoderms a radical metamorphosis results in dramatically different adults. Coloniality has evolved several times repeatedly in the tunicates and has also evolved in hemichordates. The evolution of coloniality changes a suite of characteristics in larval and adult features in ways not well understood. Tunicate larvae probably evolved independently and may not represent the 'ancestral' chordate. Hox genes specify anterior-posterior polarity in the deuterostomes, but the cluster has evolved independently in the Ambulacraria, Tunicata and Chordata (lancelets and vertebrates). Vertebrates have increased mesoderm and may have co-opted brachyury $T$ and nodal into mesoderm for increased cell movement into the blastopore during gastrulation. Further inquiry into the evolution of developmental processes may give us a better understanding of the evolution of divergent deuterostome body plans.

\section{Acknowledgements}

I would like to thank the editors of this volume, Paul Brakefield and Vernon French, for their patience during the writing of this paper. Richard Strathmann and Alex Eaves are thanked for many discussions on the ciliary feeding and swimming mechanisms found in echinoderm and tornaria larvae and their comments on the manuscript. Kirk Zigler is thanked for the beautiful photos of echinoderm development in Figures 3 and 4, taken in the FHL Embryology Course of 2001. Students in the FHL Evo-Devo Course of 2001 are thanked for some of the other embryo photos and for the very unique piñata. Bernie Degnan is thanked for exchanging ideas of the bi-functional ascidian lifestyle. Liyun 'Roy' Zeng is thanked for constructing Figure 1. J Muse Davis is thanked for Figures 6 and 7. Members of my laboratory, Federico Brown, Marla Davis Robinson, Amanda Rychel and Liyun 'Roy' Zeng are thanked for many deuterostome evolution discussions and for critical reading of the manuscript. The University of Washington Biology Department and Smithsonian Marine Station at Fort Pierce get special thanks for sabbatical funding. This is Contribution no. 655 of the Smithsonian Marine Station at Fort Pierce, Florida.

\section{References}

Amores A, Force A, Yan Y-L, Joly L, Amemiya C, Fritz A et al (1998). Zebrafish Hox clusters and vertebrate genome duplication. Science 282: 1711-1714.

Arenas-Mena C, Martinez P, Cameron RA, Davidson EH (1998). Expression of the Hox gene complex in the indirect development of a sea urchin. Proc Natl Acad Sci 95: 1306213067.

Arendt D, Technau U, Wittbrodt J (2001). Evolution of the bilaterian larval foregut. Nature 409: 81-85.

Bassham S, Postlethwait J (2000). Brachyury (T) expression in embryos of a larvacean urochordate, Oikopleura dioica, and the ancestral role of T. Develop Biol 220: 322-332.

Bishop JDD, Manríquez PH, Hughes RN (2000). Water-borne sperm trigger vitellogenic egg growth in two sessile marine invertebrates. Proc Natl Acad Sci Ser B 267: 1165-1169.

Blair JE, Hedges SB (2005). Molecular phylogeny and divergence times of deuterostome animals. Mol Biol Evol 22: 22752284.

Bourlat SJ, Nielsen C, Lockyer AE, Timothy D, Littlewood J, Telford MJ (2003). Xenoturbella is a deuterostome that eats molluscs. Nature 424: 925-928.

Cameron CB, Garey JR, Swalla BJ (2000). Evolution of the chordate body plan: new insights from phylogenetic analyses of deuterostome phyla. Proc Natl Acad Sci 97: 4469-4474.

Carroll SB (1995). Homeotic genes and the evolution of arthropods and chordates. Nature 376: 479-485.

Chea HK, Wright CV, Swalla BJ (2005). Nodal signalling and the evolution of deuterostome gastrulation. Develop Dyn 234: 269-278.

Dautov SSH, Nezlin LP (1992). Nervous system of the tornaria larva (Hemichordata: Enteropneusta). A histochemical and ultrastructural study. Biol Bull 183: 463-475.

Davidson B, Jacobs MW, Swalla BJ (2004). The individual as a module: metazoan evolution and coloniality. In: Schlosser G, Wagner G (eds) Modularity in Development and Evolution. University of Chicago Press: Chicago, IL. pp 443-465. 
Davidson EH, Erwin DH (2006). Gene regulatory networks and the evolution of animal body plans. Science 311: 796-800.

Delsuc F, Brinkmann H, Chourrout D, Philippe H (2006). Tunicates and not cephalochordates are the closest living relatives of vertebrates. Nature 439: 965-968.

Di Gregorio A, Spagnuolo A, Ristoratore F, Pischetola M, Francesco A, Branno $M$ et al (1995). Cloning of ascidian homeobox genes provides evidence for a primordial chordate cluster. Gene 156: 253-257.

Duboc V, Röttinger E, Besnardeau L, Lepage T (2004). Nodal and BMP2/4 signaling organizes the oral-aboral axis of the sea urchin embryo. Dev Cell 6: 397-410.

Duboc V, Röttinger E, Lapraz F, Besnardeau L, Lepage T (2005) Left-right asymmetry in the sea urchin embryo is regulated by nodal signaling on the right side. Dev Cell 9: 147-158.

Eaves AA, Palmer AR (2003). Reproduction: widespread cloning in echinoderm larvae. Nature 425: 146.

Ettensohn CA, Wessel GM, Wray GA (2004). The invertebrate deuterostomes: an introduction to their phylogeny, reproduction, development, and genomics. Methods Cell Biol 74: 1-13.

Flowers VL, Courteau GR, Poustka AJ, Weng W, Venuti JM (2004). Nodal/Activin signaling establishes oral-aboral polarity in the early sea urchin embryo. Dev Dyn 231: 727-740.

Gerhart J, Lowe C, Kirschner M (2005). Hemichordates and the origin of chordates. Curr Opin Genet Dev 15: 461-467.

Hadfield MG (1975). Chapter 7 Hemichordata. In: Giese AC, Pearse JS (eds) Reproduction of Marine Invertebrates II Academic Press: New York. pp 255-268.

Halanych KM (1995). The phylogenetic position of the pterobranch hemichordates based on $18 \mathrm{~S}$ rDNA sequence data. Mol Phylogenet Evol 4: 72-76.

Holland PWH, Garcia-Fernandez J, Williams NA, Sidow A (1994). Gene duplications and the origins of vertebrate development. Development Suppl 125-133.

Holland PWH, Koschorz B, Holland LZ, Herrmann BG (1995) Conservation of Brachyury $(\mathrm{T})$ genes in amphioxus and vertebrates: developmental and evolutionary implications. Development 121: 4283-4291.

Hotta K, Takahashi H, Asakura T, Saitoh B, Takatori N, Satou Y et al (2000). Characterization of Brachyury-downstream notochord genes in the Ciona intestinalis embryo. Develop Biol 224: 69-80.

Kardong KV (2006). Vertebrates: Comparative Anatomy, Function, Evolution, 4th edn. McGraw-Hill: Boston MA. p 63.

Knott KE, Balser EJ, Jaekle WB, Wray GA (2003). Identification of asteroid genera with species capable of larval cloning. Biol Bull 204: 246-255.

Laird DJ, De Tomaso AW, Weisman IL (2005). Stem cells are units of natural selection in a colonial ascidian. Cell 123 1351-1360.

Lengyel JA, Iwaki DD (2002). It takes guts: the Drosophila hindgut as a model system for organogenesis. Dev Biol 243: 1-19.

Long S, Martinez P, Chen W-C, Thorndyke M, Byrne M (2003). Evolution of echinoderms may not have required modification of the ancestral deuterostome $H O X$ gene cluster: first report of PG4 and PG5 Hox orthologues in echinoderms. Develop Genes Evol 213: 573-576.

Lowe CJ, Wu M, Salic A, Evans L, Lander E, Stange-Thomann N et al (2003). Anteroposterior patterning in hemichordates and the origins of the chordate nervous system. Cell 113: 853-865.

Martinez P, Rast JP, Arenas-Mena C, Davidson EH (1999). Organization of an echinoderm Hox gene cluster. Proc Natl Acad Sci 96: 1469-1474.

Meyer A, Malaga-Trillo E (1999). Vertebrate genomics: more fishy tales about Hox genes. Curr Biol 9: R210-R213.

Morgan TH (1891). The growth and metamorphosis of Tornaria. J Morphol 5: 407-458.
Morris VB, Byrne M (2005). Involvement of two Hox genes and Otx in echinoderm body-plan morphogenesis in the sea urchin Holopneustes purpurescens. J Exp Zool B Mol Dev Evol 304: 456-467.

Nielsen C (1997). Origin and evolution of animal life cycles. Biol Rev 73: 125-155.

Passamaneck YJ, Di Gregario A (2005). Ciona intestinalis: chordate development made simple. Dev Dyn 233: 1-19.

Peterson KJ (2004). Isolation of Hox and Parahox genes in the hemichordate Ptychodera flava and the evolution of deuterostome Hox genes. Mol Phy Evol 31: 1208-1215.

Peterson KJ, Cameron RA, Tagawa K, Satoh N, Davidson EH (1999a). A comparative molecular approach to mesodermal patterning in basal deuterostomes: the expression pattern of Brachyury in the enteropneust hemichordate Ptychodera flava. Development 126: 85-95.

Peterson KJ, Harada Y, Cameron RA, Davidson EH (1999b). Expression pattern of Brachyury and Not in the sea urchin: comparative implications for the origins of mesoderm in the basal deuterostomes. Develop Biol 207: 419-431.

Philippe H, Lartillot N, Brinkmann H (2005). Multigene analyses of bilaterian animals corroborate the monophyly of ecdysozoa, lophotrochozoa, and protostomia. Mol Biol Evol 22: $1246-1253$

Popodi E, Kissinger JC, Andrews ME, Raff RA (1996). Sea urchin Hox genes: insights into the ancestral Hox cluster. Mol Biol Evol 13: 1078-1086.

Rabinowitz C, Rinkevich B (2003). Epithelial cell cultures from Botryllus schlosseri palleal buds: accomplishments and challenges. Methods Cell Sci 25: 137-148.

Rychel AL, Smith SE, Shimamoto HT, Swalla BJ (2006). Evolution and development of the chordates: collagen and pharyngeal cartilage. Mol Biol Evol 23: 1-9.

Schaeffer B (1987). Deuterostome monophyly and phylogeny. Evol Biol 21: 179-235.

Shoguchi E, Satoh N, Maruyama YK (1999). Pattern of Brachyury gene expression in starfish embryos resembles that of hemichordate embryos but not of sea urchin embryos. Mech Dev 82: 185-189.

Smith AB, Peterson KJ, Wray G, Littlewood DTJ (2004). From bilateral symmetry to pentaradiality: the phylogeny of hemichordates and echinoderms. In: Cracraft J, Donoghue MJ (eds) Assembling the Tree of Life. Oxford Press: New York. pp 365-383.

Smith JL, Schoenwolf GC (1989). Notochordal induction of cell wedging in the chick neural plate and its role in neural tube formation. J Exp Zool 250: 49-62.

Spagnuolo A, Ristoratore F, Di Gregorio A, Aniello F, Branno M, Di Lauro R (2003). Unusual number and genomic organization of Hox genes in the tunicate Ciona intestinalis. Gene 309: 71-79.

Strathmann RR, Eernisse DJ (1994). What molecular phylogenies tell us about the evolution of larval forms. Amer Zool 34: 502-512.

Swalla BJ (2006). 'New insights into vertebrate origins'. In: Sally Moody (ed) Principles of Developmental Genetics. Elsevier Science/Academic Press (in press)

Swalla BJ, Cameron C, Corley L, Garey J (2000). Urochordates are monophyletic within the deuterostomes. Syst Biol 49: 52-64.

Tagawa K, Humphreys T, Satoh N (1998). Novel pattern of gene expression in hemichordate embryos. Mech Dev 75: 139-143.

Technau U, Scholz CB (2003). Origin and evolution of endoderm and mesoderm. Int J Dev Biol 47: 531-539.

Urata M, Yamaguchi M (2004). The development of the enteropneust hemichordate Balanoglossus misakiensis KUWANO. Zoolog Sci 21: 533-540.

Wada H, Garcia-Fernandez J, Holland PWH (1999). Colinear and segmental expression of amphioxus Hox genes. Development 213: 131-141.

Wada H, Makabe KW, Nakauchi M, Satoh N (1992). Phylogenetic relationships between solitary and colonial ascidians, as 
inferred from the sequence of the central region of their respective 18S rDNAs. Biol Bull 183: 448-455.

Wilkinson DG, Bhatt S, Herrmann BG (1990). Expression pattern of the mouse $\mathrm{T}$ gene and its role in mesoderm formation. Nature 343: 657-659.

Winchell CJ, Sullivan J, Cameron CB, Swalla BJ, Mallatt J (2002). Evaluating hypotheses of deuterostome phylogeny and chordate evolution with new LSU and SSU ribosomal DNA data. Mol Biol Evol 19: 762-776.

Yasuo H, Satoh N (1993). Function of the vertebrate $T$ gene. Nature 364: 582-583.

Yasuo H, Satoh N (1994). An ascidian homolog of the mouse Brachyury $(T)$ gene is expressed exclusively in notochord cells at the fate restricted stage. Develop Growth Differ 36: 9-18.

Yokobori S, Kurabayashi A, Neilan BA, Maruyama T, Hirose E (2006). Multiple origins of the ascidian-Prochloron symbiosis: molecular phylogeny of photosymbiotic and non-symbiotic colonial ascidians inferred from $18 \mathrm{~S}$ rDNA sequences. Mol Phylogenet Evol 40: 8-19.

Zeng L, Jacobs MW, Swalla BJ (2006). Coloniality has evolved once in Stolidobranch ascidians. Int Comp Biol 46: 255-268.

Zeng L, Swalla BJ (2005). Molecular phylogeny of the protochordates: chordate evolution. Can J Zool 83: 24-33.

\section{Recommended resources}

Biology of the Protochordata: A collection of reviews published in the Canadian Journal of Zoology, Vol 83. http://cjz.nrc.ca.

The Invertebrate Deuterostomes: An Introduction to their Phylogeny, Reproduction, Development, and Genomics. (2004) Ettensohn CA, Wessel GM, Wray GA (eds) Methods Cell Biol, Vol 74.

Tree of Life http://tolweb.org/tree?group= Deuterostomia. 